\title{
Pesquisa em inteligência competitiva organizacional: utilizando a análise de conteúdo para a coleta e análise de dados - Parte II
}

\author{
Research in organizational competitive \\ intelligence: using content analysis for \\ the data collection and analysis - Part II
}

Marta Lígia Pomim VALENTIM ${ }^{1}$

Adriana Rosecler ALCARÁ ${ }^{1}$

Brígida Maria Nogueira CERVANTES ${ }^{1}$

Elizabeth Leão de CARVALHO ${ }^{1}$

Heliéte Dominguez GARCIA ${ }^{1}$

José Carlos DALMAS'

Letícia Gorri MOLINA ${ }^{1}$

Lívia Aparecida Ferreira LENZI ${ }^{1}$

Maria Elisabete CATARINO ${ }^{1}$

Maria Inês TOMAÉL ${ }^{1}$

\section{RE S U M O}

Para a realização da pesquisa de campo em inteligência competitiva organizacional, optou-se pela análise de conteúdo para a coleta e análise de dados. Duas técnicas da análise de conteúdo foram utilizadas: a análise léxica e a análise categorial (temas). A análise léxica tem enfoque quantitativo e seu

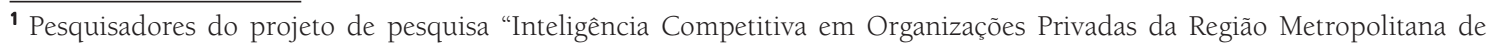
Londrina" e do Grupo de Pesquisa "Informação, Conhecimento e Inteligência Organizacional" da Universidade Estadual de Londrina. Campus Universitário, Cidade Universitária, 8651-970, Londrina, PR, Brasil.

Agradecimentos:

Fabiana SALA; Guilherme Baracat UEMURA; João Vítor Vieira GELINSKI; Josana Souza CARLOS e Luana Maia WOIDA são bolsistas de iniciação científica do projeto de pesquisa "Inteligência Competitiva em Organizações Privadas da Região Metropolitana de Londrina" e do Grupo de Pesquisa "Informação, Conhecimento e Inteligência Organizacional" da Universidade Estadual de Londrina (UEL).

Fabiana Aparecida NICOLINI; Jorge Luis RODRIGUES e Natan Tiago Batista SERZEDELLO são colaboradores do projeto de pesquisa "Inteligência Competitiva em Organizações Privadas da Região Metropolitana de Londrina" e do Grupo de Pesquisa "Informação, Conhecimento e Inteligência Organizacional".

Recebido e aceito para publicação em 28/6/2005.
} 
objetivo é mensurar termos como: substantivos, adjetivos, verbos etc., relacionados ao processo de inteligência competitiva organizacional, encontrados no instrumento de coleta de dados. Nesta pesquisa, a análise categorial, de enfoque qualitativo, tem como objetivo investigar temas relacionados à inteligência competitiva organizacional, encontrados nos discursos dos sujeitos pesquisados.

Palavras-chave: inteligência competitiva, metodologia de pesquisa, análise de conteúdo, análise léxica, análise categorial, coleta e análise de dados.

\section{A B S T R A C T}

To accomplish this field research in organizational competitive intelligence, the researchers opted for the content analysis method, which is designed for data collection and analysis. Two techniques of the content analysis were used: lexical analysis and categories analysis (themes). The lexical analysis has quantitative focus and it searches for terms such as: nouns, adjectives, verbs, etc., related to the organizational competitive intelligence process, found in the instrument of data collection. In this research, the categories analysis has a qualitative focus and its objective is to investigate themes related to the organizational competitive intelligence, found in the speeches of the researched authors.

Key words: competitive intelligence, research methodology, content analysis, lexical analysis, categories analysis, data collection and analysis.

\section{Comunicação informacional}

Assim como a cultura e o clima organizacional devem ser positivos em relação à geração, compartilhamento e uso da informação, a comunicação informacional exerce uma função primordial no processo de inteligência competitiva (IC). É por meio dela, da comunicação, que as pessoas relacionam-se e interagem no ambiente corporativo (VALENTIM, 2004a, p.1).

A comunicação informacional é entendida como um processo contínuo que alimenta, reconhece, gera, usa e compartilha dados, informações e conhecimentos existentes no ambiente corporativo.

Os modelos de gestão organizacional, influenciam os modelos comunicacionais, que por sua vez influenciam as pessoas da organização, no sentido de facilitar ou não o processo de I.C. Por outro lado, as pessoas também influenciam a comunicação organizacional de modo a propiciar maior ou menor efetividade ao processo de I.C. (VALENTIM, 2003a, p.1).

Outro aspecto recorrente na literatura da área refere-se à importância da comunicação para a construção de significado dos fenômenos corporativos:

A comunicação existe a partir de um contexto, de um espaço. O espaço corporativo é sem dúvida um espaço comunicacional, portanto, a comunicação existe e se funda a partir da relação entre os indivíduos da organização, cada um influenciando sobremaneira o outro, e juntos constroem diferentes significados, que resultam na cultura organizacional. No entanto, é importante mencionar que este processo inicia-se na comunicação entre as pessoas. (VALENTIM, 2004a, p.1). 
As pessoas, atores do processo comunicacional corporativo, são, portanto, os impulsionadores de contextos informacionais que permeiam a organização.

As subcategorias identificadas como essenciais para a construção do módulo do instrumento de coleta e análise de dados são: 1) modelos comunicacionais; 2) uso da comunicação como instrumento de divulgação das normas da organização; 3) cultura em relação à comunicação; 4) redes de pessoas em relação à comunicação; 5) tipologias comunicacionais.

A subcategoria referente aos modelos comunicacionais é importante porque estes estão conectados com os modelos de gestão, ou seja, o modelo de gestão da organização influenciará sobremaneira os modelos comunicacionais. Pode-se observar, por exemplo, que as organizações baseadas em tecnologias de informação e comunicação, utilizam modelos comunicacionais também baseados em tecnologias.

O uso da comunicação como instrumento de divulgação das normas da organização, segunda subcategoria definida, representa a forma com que a organização usa a comunicação para disseminar as normas corporativas.

Conforme já foi mencionado anteriormente, no que se refere à comunicação, a cultura é elemento fundamental de análise, pois esta vai demonstrar não só como as pessoas da organização atuam positivamente em relação ao compartilhamento da informação, mas também identificará as competências existentes para o uso da comunicação corporativa.

Nesse sentido, a análise da rede de pessoas em relação à comunicação, ou seja, a quarta subcategoria, esclarecerá de que forma a comunicação constitui rede ou redes de relacionamento no espaço corporativo.

Aúltima subcategoria pretende identificar, no ambiente organizacional, quais são as tipologias comunicacionais mais usadas entre as pessoas que compõem o espaço corporativo, quantificando-as e qualificando-as na medida do possível.

\section{Prospecção e monitoramento informacional}

A prospecção e o monitoramento informacional são etapas fundamentais ao processo de IC. O termo prospecção informacional é entendido como

"[...] o método ou técnica que visa à identificação inicial de dados, informação e conhecimento relevantes para a organização. Monitoramento informacional é o método ou técnica de observação e acompanhamento constante de dados, informação e conhecimento relevantes ao negócio da organização". (VALENTIM; MOLINA, 2004c).

O Ministério da Ciência e Tecnologia (2003), mais especificamente o Programa ProspeCTar, define prospecção como um processo contínuo de pensar o futuro, e fornecer subsídios para a melhor tomada de decisão, instruindo ainda sobre como aspectos econômicos, sociais, científicos e tecnológicos podem interagir para a solução de problemas socioeconômicos. A atividade de prospecção possibilita estabelecer um mapa inicial de fontes de dados, informação e conhecimento essenciais ao negócio da organização, enquanto a atividade de monitoramento informacional irá dar consistência e continuidade a esse processo.

O termo monitoramento tem origem na corrente americana, similar à corrente francesa veille (vigília). Para Palop e Vicente (1999, p.22), o monitoramento é um esforço sistemático e organizado pela empresa para observação, captação, análise e recuperação de informações. De acordo com os autores, várias atividades 
podem ser desenvolvidas, visando-se detectar as necessidades da organização, para a formulação de estratégias competitivas, tais como: pesquisar fontes de informação e bases de dados especializadas; mapear as redes de informação interna e externa à organização; conhecer e gerenciar os fluxos informacionais interno e externo à organização; organizar e tratar as informações, agregando-lhes valor; selecionar, tratar e disseminar informações relevantes para a organização; elaborar produtos informacionais adequados às necessidades dos usuários etc., enfim, atividades que são imprescindíveis à competitividade da organização em relação à sua atuação no mercado.

Para o processo de elaboração do módulo foram definidas quatro subcategorias: 1) mapeamento das necessidades informacionais; 2) filtragem da informação; 3) agregação de valor e 4) disseminação da informação.

De acordo com a literatura pesquisada, as subcategorias identificadas são a base da estruturação da atividade de prospecção e monitoramento informacional. O mapeamento das necessidades informacionais é a primeira ação a ser realizada no processo de inteligência competitiva, pois a partir desse mapeamento é possível identificar e coletar informação em fontes formais e informais, analisar e selecionar as melhores fontes segundo critérios preestabelecidos tais como acessibilidade, custo, qualidade do conteúdo, cobertura e abrangência. A filtragem informacional seleciona, dentre um grande número de dados e informações, aqueles que têm potencial relevância. Para Kielgast e Hubbard (1997, p.273), "[...] o processo de transformar dados sem nenhum significado, em informação útil é um processo que agrega valor, havendo quatro atividades significativas neste processo: organização da informação, análise, síntese e julgamento".

A fase de disseminação é muito importante, porquanto a informação deve ser precisa, ter rigor científico, tecnológico e estratégico, e estar acessível para apoiar a tomada de decisão. Para isso, a forma de apresentação dos produtos e serviços de inteligência deve ser planejada tanto em relação ao seu conteúdo (tático e/ou estratégico), quanto em relação ao perfil do destinatário do produto/serviço.

\section{Gestão da informação}

Para que a organização alcance sucesso no processo de tomada de decisão, ela necessita de informações úteis, consistentes, confiáveis e acessíveis, uma vez que todas as funções corporativas estão, ou deveriam estar, direta ou indiretamente, ligadas à missão e aos objetivos. Nesse sentido, todos os níveis da organização necessitam de informações para desenvolver suas atividades, sejam elas táticas ou operacionais.

Gestão da informação é um processo informacional apoiado nos fluxos formais corporativos, ou seja, no conhecimento explícito, sendo seu foco o negócio da organização.

A gestão da informação envolve um conjunto de atividades estruturadas que incluem a obtenção, geração, distribuição e uso da informação e do conhecimento, e representa o controle e gerenciamento do ambiente informacional na corporação, incluindo tecnologia de informação e telecomunicação, a informação propriamente dita e os recursos humanos envolvidos em qualquer dessas fases (DAVENPORT, 1998; CIANCONI, 1999).

Gerenciar a informação como um recurso no ambiente interno das organizações implica, primeiramente, a identificação das necessidades informacionais das pessoas da organização, tendo como foco as metas e diretrizes organizacionais. O segundo passo visa criar metodologias para mapear e reconhecer os fluxos formais de informação nos diferentes níveis hierárquicos, para finalmente buscar ferramentas (tecnologias de informação), objetivando coletar, tratar, 
analisar, armazenar, disseminar e mediar as informações, para, desse modo, subsidiar o processo decisório e as atividades cotidianas desenvolvidas voltadas aos produtos e serviços da corporação (CARVALHO, 2001).

Para gerenciar a informação como recurso, surgiu na década de 80, nos Estados Unidos e na Inglaterra, o Gerenciamento de Recursos Informacionais, como ficou mais conhecido. $\mathrm{O}$ Gerenciamento de Recursos Informacionais (GRI) tem como objetivo propiciar à organização conhecer e utilizar, da melhor maneira, os recursos informacionais disponíveis.

Burk Jr. e Horton (1988, p.9) apresentam a definição de GRI como:

Processo dentro do segmento da gestão da informação que serve ao interesse corporativo. O GRI persegue associar a informação para benefício da organização em sua totalidade, mediante a exploração, desenvolvimento e otimização dos recursos de informação. Os interesses da organização são geralmente manifestados pelas metas e objetivos corporativos. Sendo assim, GRI é o elo de ligação gerencial que conecta os recursos de informação corporativos com as metas e objetivos da organização.

Para Cianconi (1999, p.40), o GRI "é uma das fases do processo de administrar informações de modo estratégico, ou seja, usando a inteligência, visando à competitividade".

Após estudos de autores como Burk Jr. e Horton Jr. (1988), Ponjuán Dante (1998), Davenport (1998), Cianconi (1999), foram definidas as seguintes subcategorias para compor o módulo do instrumento de coleta de dados: 1) diretrizes para administrar a informação interna; 2) coleta de informações (fluxos formais); 3) organização da informação (tecnologia) e 4) disseminação e mediação da informação.

A primeira subcategoria preocupou-se em verificar se a empresa possui uma visão estratégica informacional. Chiavegatto (1999, p.62) explica quais aspectos constituem esta visão estratégica, de importância para a organização: a "iniciativa de antecipar as necessidades de informação; gerenciar as informações que circulam; preocupação com a formalização e priorização da demanda; busca do estreito relacionamento entre gerente e administradores; uso de técnicas ou métodos para levantamento". Nesse sentido, pretende-se verificar ainda, se a informação é considerada um recurso também no âmbito da empresa (PONJUÁN DANTE, 1998, p.35).

Diretrizes ou políticas de acesso à informação são fundamentais para a gestão da informação, uma vez que contemplam desde as normas de acesso e uso da informação até o respeito à propriedade intelectual. Visam, portanto, assegurar não só a maior eficiência dos sistemas informacionais, mas também a eficácia dos resultados obtidos por meio destes recursos informacionais.

As subcategorias 2, 3 e 4 foram identificadas a partir da fundamentação teórica. Valentim et al. (2003) afirmam que, no processo de IC, tendo como foco o negócio da organização, a gestão da informação trabalha no âmbito do conhecimento explícito, essencialmente com os fluxos formais de informação, os quais são: prospecção, seleção e obtenção da informação; mapeamento e reconhecimento dos fluxos formais de informação; tratamento, análise e armazenamento da informação utilizando-se de tecnologias de informação; disseminação e mediação da informação ao público interessado; criação e disponibilização de produtos e serviços de informação.

Essas subcategorias identificarão qual a forma de obter informações, quais tipos de informação se necessitam; quais os fluxos informacionais formais existentes na empresa; quais as tecnologias de informação utilizadas para o tratamento, análise e armazenamento da informação; e em que meios as informações são divulgadas no âmbito corporativo. 
Nesse contexto, acredita-se que a partir dos resultados obtidos a partir desse módulo será possível identificar se as empresas atribuem valor à informação, gerenciando-a como qualquer outro recurso corporativo.

\section{Gestão do conhecimento}

Em conseqüência das novas necessidades advindas de um mercado globalizado, o capital intelectual passa a ser reconhecido pelas organizações como um ativo intangível, uma vez que é insumo básico para a implementação de abordagens gerenciais voltadas ao conhecimento.

Nonaka (1997, p.65), ademais de outros autores, entende a gestão do conhecimento (GC) organizacional como um sistema que abrange todos os processos relacionados ao fomento, captação, sistematização e disseminação do conhecimento no ambiente corporativo, de forma a auxiliar no processo de tomada de decisão e inovação e, conseqüentemente, na obtenção de vantagem competitiva.

A efetividade desse modelo de gestão está fortemente vinculada a comportamentos e ações individuais e coletivas; portanto, o contexto organizacional exerce grande influência nesse processo, pois se constitui em um:

Conjunto de estratégias para criar, adquirir, compartilhar e utilizar ativos de conhecimento, bem como estabelecer fluxos que garantam a informação necessária no tempo e formato adequados, a fim de auxiliar na geração de idéias, solução de problemas e tomada de decisão. (VALENTIM, 2003b, p.1).

Terra (2000, p.55) mostra a importância de a organização assumir uma postura estimulante perante as pessoas. Conseqüentemente, estabeleceu-se como primeira subcategoria para o módulo do instrumento de coleta e análise de dados, a motivação.

A necessidade de haver, por parte do indivíduo, a responsabilidade pelo próprio desenvolvimento é sustentada por Teixeira Filho (2000, p.75), que também amplia essas responsabilidades para a organização. Desse modo, definiu-se a segunda subcategoria como: o comprometimento.

Conforme Krogh, Ichijo e Nonaka (2001, p.82), o contentamento, a realização e a aceitação do indivíduo em relação às atividades que desenvolve na organização, constituem elementos de grande peso para a criação de um contexto capacitante e gerador de conhecimento. Assim foi constituída a terceira subcategoria: a satisfação.

Visão holística e processamento relacional são características que Terra (2000, p.62) afirma serem extremamente relevantes para o processo de GC, justamente por estarem conectados aos comportamentos positivos em relação à aprendizagem. Devido a isto, optou-se por definir a quarta subcategoria como: o aprendizado.

Por fim, com base no raciocínio de Choo (2003, p.30), segundo o qual a cultura de integração na organização é o alicerce para o trabalho em equipe e compartilhamento de pressuposições que resultam em objetos de significado, percebeu-se a necessidade de estabelecer uma última subcategoria: compartiIhamento de conhecimento.

Em termos gerais, ao longo da construção do módulo de coleta de dados voltado à GC, observou-se a necessidade de mudanças no enunciado e na estrutura de algumas questões, visando facilitar a compreensão por parte dos sujeitos de pesquisa, bem como focar melhor os dados necessários à pesquisa. Contudo, apesar dessas modificações na estrutura terem sido feitas, as subcategorias iniciais de base foram mantidas.

\section{Inovação e redes}

O desenvolvimento sustentável da inovação tornou-se imprescindível para as empresas 
que querem alcançar e manter a competitividade. Na busca de vantagem competitiva, a apropriação do conhecimento científico pelas empresas tornou-se questão de sobrevivência. Para isso, a identificação de oportunidades requer a análise do entorno empresarial, em busca de subsídios para que a inovação seja um instrumento a mais de ação competitiva.

Inovar é buscar o novo, é implementar uma novidade. Demantova (2001, p.95), caracteriza a inovação tecnológica como "novo produto, processo ou sistema que tem potencial para criar um mercado inteiramente novo, ou mudar um mercado existente, de tal maneira a criar padrões de competitividade ou de comportamento do consumidor". Complementando essa conceituação, Dosi (1988) acrescenta que a inovação constitui-se pela pesquisa, descoberta, verificação, desenvolvimento, imitação e aceitação de novos produtos, novos processos e novas técnicas organizacionais.

Para Schumpeter (1982), o desenvolvimento capitalista é um processo de mudança, cujo motor é a inovação. O desenvolvimento econômico pressupõe uma ruptura do equilíbrio preexistente - a introdução de alguma forma de inovação e a constituição de uma nova e inerentemente instável situação de equilíbrio -, situação sujeita à alteração a qualquer momento. A inovação é um dos principais requisitos da competitividade e, portanto, força motriz do negócio da organização. Ainda de acordo com o autor,

Transformar o sistema econômico é realizar novas combinações ou inovações, ou seja, a introdução de um novo produto ou um novo método de produção; a abertura de um novo mercado; a descoberta ou conquista de uma nova fonte de matéria-prima ou a introdução de uma nova estrutura de mercado. (BERNARDES 1999, p.89).

Para o desenvolvimento do módulo de coleta dos dados, especificamente no que se refere a inovação e redes, estabeleceu-se quatro subcategorias: 1) inovação e o processo de inteligência competitiva; 2) relações entre gestão do conhecimento e inovação; 3) sistema local de inovação; 4) redes de relacionamento.

$\mathrm{Na}$ perspectiva de Krücken-Pereira, Debiasi e Abreu (2001), a inteligência competitiva constitui-se em uma das ferramentas para o processo de inovação, "pois possibilita observar o mercado, analisar as estratégias de seus competidores e suas repercussões, o comportamento e as tendências dos consumidores, seus valores, expectativas e necessidades".

Os resultados encontrados na pesquisa de Krücken-Pereira, Debiasi e Abreu (2001) e de Havehga e Botha (2003, p.2) demonstram que a inteligência competitiva é um recurso imprescindível para a inovação e está em sintonia com a subcategoria 'inovação e o processo de inteligência competitiva'. É importante destacar que essa subcategoria visa, ainda, buscar novos aportes, ainda não estudados, para a relação da inovação com a inteligência competitiva.

A segunda subcategoria 'relações entre gestão do conhecimento e inovação' está fundamentada no seguinte preceito: as empresas precisam aprender a utilizar as competências que detêm, para inovarem e serem mais competitivas. Adams e Lamont (2003, p.148) estudaram a absorção e transformação, pelas organizações, de suas capacitações tecnológicas em inovações, com ênfase em seus sistemas de gestão do conhecimento. Na mesma linha de estudo, Correia e Sarmento (2003, p.11) investigaram as influências que a gestão do conhecimento recebe e exerce; baseadas nessa investigação, verificaram que uma das áreas que compõem esse meio é a gestão da inovação. As autoras afirmam que a gestão do conhecimento emerge como uma área pluri- e interdisciplinar. Em suma, uma economia baseada em conhecimento gera inovação que impulsiona a competitividade, a qual, por sua vez, acelera o processo de pesquisa e desenvolvimento (P\&D), tornando-se, portanto, 
cada vez mais dependente de um fluxo contínuo de conhecimento. Assim, a gestão do conhecimento também representa um importante recurso para a inovação.

A subcategoria referente ao 'sistema local de inovação' está amparada em Johnson e Lundvall (2000, p.1), os quais afirmam que um sistema de inovação requer estratégias para a análise de todas as partes da economia que contribuem para a construção de competências e inovação, especialmente quando seu foco está nas ligações e ações comuns entre as partes que formam o sistema como um todo. Esse é um dos ângulos de interesse deste estudo: conhecer o sistema de inovação da região, que se constitui pelas interações, relacionamentos e complementaridades entre diversos agentes que compõem o sistema. O sistema assim formado torna-se uma grande rede, constituída por outras menores, que a sustentam e possibilitam a cooperação na produção e uso do conhecimento entre as organizações, construindo suas competências.

O reconhecimento do sistema local de inovação tem relevância porque propiciará distinguir quantas empresas inovam, em que inovam, a quais setores pertencem, quais as similaridades das inovações, qual o montante de recursos que aplicam em P\&D, quais as relações e interações presentes no desenvolvimento de suas atividades, bem como quais as parcerias que firmam entre si.

A última subcategoria deste módulo compreende as 'redes de relacionamento' entre as empresas, que se caracterizam como redes sociais. Segundo definem Garton, Haythornthwaite e Wellman (1997), 'rede social' refere-se a um conjunto de organizações (ou pessoas ou outras entidades sociais) conectadas por relacionamentos sociais, motivadas pelas relações de trabalho e troca de informação ou amizade. Uma rede é um conjunto de relações (elos ou vínculos) entre uma série definida de elementos (nós - indivíduos, organizações, etc.) com interesses e/ou objetivos comuns (MOLINA, 2004, p.36).

O relacionamento que visa à cooperação estabelece a nova forma organizacional, em rede. Bernardes e Almeida (1999, p.102) utilizam-se de Debresson e Amese (1991) para definir empresa-rede. Para esses autores, a configuração de empresa-rede pressupõe "o desenvolvimento de formas reticulares de organização nas quais se verifica o aparecimento de teias ou anéis de cooperação empresarial". As redes são construídas mobilizando-se pessoas, organizações e recursos que, juntos, compartilham esforços e benefícios em prol de ações que fortaleçam o conjunto.

O conceito de rede aproxima-se do conceito de sistema local de inovação, pois ambos são distinguidos por termos como: ações comuns, benefícios mútuos, inter-relações, cooperação, etc.

É na relação entre esses conceitos que esta pesquisa se apóia, para apresentar particularidades de inovações e de redes, as quais, no âmbito do sistema local de inovação são complementares.

\section{Tecnologias de Informação}

Informações precisas e atualizadas disponíveis para a tomada de decisão nas organizações, são o diferencial que torna tais empresas competitivas, num contexto em que o mercado as pressiona a incorporar e aprimorar as tecnologias de ponta, a buscar novos modelos de organização, gestão e tecnologia, a ampliar conhecimentos e a inovar, para prosperarem com sucesso nos diversos segmentos produtivos.

Chorafas (apud ALBERTIN, 2001, p.44) afirma:

O ambiente digital altera significativamente a natureza dos negócios, sendo três desses pilares da infraestrutura eletrônicos: computadores, 
comunicações e software. Os outros são organizacionais: planejamento estratégico, marketing agressivo e capacidade de assimilar os aspectos relacionados com computadores.

Pode-se afirmar que os três pilares eletrônicos somados à gestão de dados e informações formam o conjunto denominado de tecnologias da informação (Tl's). Dentre os conceitos de TI existentes na literatura, para este estudo optou-se pela definição de autoria de Rezende e Pereira (2002):

A TI pode ser conceituada como recursos tecnológicos e computacionais para guarda, geração e uso da informação. E está fundamentada nos seguintes componentes: hardware e seus dispositivos e periféricos; softwares e seus recursos; sistemas de telecomunicações; gestão de dados e informações.

Este conceito norteou a definição das subcategorias propostas, visto que não considera apenas os recursos físicos (softwares e hardwares), mas também os de gestão que incluem os recursos humanos e financeiros. Freitas e Lesca (1992) afirmam que o sistema de informação (SI) não se apóia apenas em hardware e software, mas no conjunto de pessoas, na própria estrutura de organização e nos procedimentos e métodos que devem permitir à organização obter as informações que necessita, em tempo hábil. Esses elementos também foram considerados para a definição das subcategorias.

Alguns estudos recentes, referem-se a casos de executivos que, no momento da tomada de decisão, apesar dos sistemas de informação disponíveis, deparam-se com o receio de errar, uma vez que o volume exagerado de informações ocasiona estresse e insegurança. Para Santos (2001), a inserção das Tl's parece ter contribuído para "exacerbar a problemática", pois, apesar do aumento de literatura sobre o assunto, poucos são os sistemas que, colocados em operação, corresponderam às expectativas.
É imprescindível entender que a implantação de um processo de inteligência competitiva (IC), nas suas diversas fases, exige planejamento e envolvimento de toda a organização. Se isto não ocorrer, de nada servirão as Tl's utilizadas.

Na construção do módulo do instrumento de coleta de dados referentes às TI's foram, portanto, definidas as seguintes subcategorias: 1) gestão/investimento em Tl's; 2) ferramentas utilizadas no processo e 3) atores/setores da organização que utilizam as Tl's.

A primeira subcategoria 'gestão/investimentos em Tl's é imprescindível para o estudo proposto, já que as Tl's influenciam o planejamento das corporações, além de ser uma das forças que acelera as mudanças relacionadas ao aumento da competitividade entre as organizações.

Explica Albertin (2001, p.43) que "as mudanças tecnológicas nas indústrias de computadores e telecomunicações têm aumentado as economias de escala e de escopo, ocasionando um profundo impacto no funcionamento das empresas".

Observa-se que as organizações de vários setores têm realizado significativos investimentos em tecnologias, passando a ter todos os seus procedimentos de produção e/ou prestação de serviços apoiados em Tl's. Assim, os empresários têm buscado mais informações sobre valor estratégico, conhecendo melhor as particularidades e as práticas da gestão desse tipo de tecnologias no ambiente corporativo.

As 'ferramentas utilizadas no processo', segunda subcategoria proposta, apóia-se em Teixeira Filho (2001) que afirma: "a empresa que melhor perceber as aplicações das tecnologias emergentes às suas operações, e que puder usar mais eficazmente a informática nos processos decisórios, terá maior vantagem competitiva em seu setor de atuação".

Seguindo esta linha de pensamento, as TI's são muito úteis para apoiar o processo de 
inteligência competitiva. Gomes e Braga (2001, p.83) também mencionam que "a tecnologia de informação apóia todas as etapas de um processo de inteligência competitiva, desde a fase de identificação das necessidades de informação, passando pela coleta, análise e disseminação, até a avaliação de produtos entregues".

A última subcategoria, relacionada aos 'atores/setores que utilizam as Tl's, verificará o ambiente corporativo sob dois aspectos: as habilidades gerais e os especialistas em TI's. Para Morris et al., citado por Maçada (2001, p.88) "não é possível estruturar uma organização eficiente apenas com a estratégia de informação e a aplicação dos recursos de Tl's. É necessário também combinar a estratégia de negócios e recursos humanos" Também é importante destacar, quanto a esta categoria, que no processo de IC necessita-se de uma equipe capacitada que auxilie a seleção, busca e tratamento da informação apoiada emTI's, objetivando a análise crítica da empresa (VARGAS; SOUZA, 2001).

\section{Atores do processo de inteligência competitiva organizacional}

Entende-se que o profissional da informação deve trabalhar em equipes multidisciplinares de IC, pois suas competências e habilidades específicas podem contribuir enormemente para o processo de IC.

Equipe multidisciplinar entendida como um conjunto de pessoas de diferentes especialidades que atuam e desenvolvem atividades de diferentes naturezas e agem como um time, visando ao compartilhamento de informação e de conhecimento para atingir os objetivos da organização. (VALENTIM, 2004b p.156).

Vários autores defendem ser necessário que os profissionais da inteligência possuam competências e habilidades que atendam as demandas informacionais. Como competências e habilidades essenciais ao profissional da informação que atuará com informação e conhecimento, podem-se citar:

- pessoais: comunicação escrita e oral, capacidade de análise, liderança [...], ser proativo, flexível, trabalhar interativamente com múltiplas organizações [...], maturidade profissional e experiência, habilidades pessoais básicas requeridas para atuação num cenário dinâmico;

- técnicas: conhecimento na área de IC, de aplicativos específicos, de pesquisa, de planejamento estratégico [...], conhecimentos de técnicas e métodos de IC [...] e de ferramentas gerenciais, tais como análises de cenários, benchmarking, prospecção tecnológica, data mining, data warehouse, bancos de dados on-line, programas estatísticos, gestão de projetos [...] e domínio da tecnologia Internet;

-experiência profissional: em marketing, em [...] Internet, em vendas, em informática, em análise de mercado [...] em gestão de produtos, em gestão de projetos, em finanças [...], em instrumentos de análise da informação e de comunicação, conhecimento do campo de atuação empresarial. (VARGAS; SOUZA, 2001).

Krogh, Ichijo e Nonaka (2001, p.20-23) denominam os profissionais da informação de 'ativistas do conhecimento', 'profissionais do conhecimento', 'trabalhadores do conhecimento', ou 'engenheiros do conhecimento'. Considere-se, ainda, que:

Das atividades desenvolvidas pelo profissional da informação no processo de IC, destacam-se atividades estratégicas, gerenciais, técnicas e humanas, e esse profissional precisa 
possuir conhecimentos específicos dos métodos, técnicas e instrumentos da área de inteligência competitiva. (VALENTIM et al., 2003, p.17).

Entendem-se, portanto, como atores de IC, todas as pessoas atuantes na organização, com formação e competências específicas, que visam o desenvolvimento de atividades informacionais relacionadas ao negócio corporativo.

Para este projeto, com o fim de construir o módulo do instrumento de coleta de dados, especificamente voltados aos atores de IC, foram identificadas na literatura indicada quatro subcategorias essenciais: 1) competências e habilidades; 2) formação profissional; 3) função/ responsabilidades; 4) setores específicos/ equipes multidisciplinares.

A primeira subcategoria pretende identificar junto aos sujeitos pesquisados quais as competências e habilidades que lhes são necessárias para atuar em ambiente corporativo, visando vantagem competitiva.

A formação dos profissionais que atuam na organização, desempenhando função ou atividades de inteligência, também foi escolhida como uma das subcategorias essenciais.

Do mesmo modo, também serão observadas as funções exercidas e as responsabilidades inerentes à função. Essa análise permitirá verificar se os profissionais estão de fato preparados para o exercício da função em termos de competências, habilidades e formação.

A última subcategoria tem como objetivo verificar se existem setores e equipes específicas atuando com inteligência competitiva, visa também examinar se o processo é centralizado ou descentralizado.

As quatro subcategorias mencionadas podem, a partir de inferências, estabelecer o perfil dos profissionais que estão desenvolvendo atividades de IC nas organizações pesquisadas.

\section{Terminologia em inteligência competitiva organizacional}

A terminologia aplicada à compilação de termos e à elaboração de instrumentos terminológicos tornou-se uma atividade de grande utilidade social, visto que contribui para solucionar problemas de informação e comunicação. A terminologia é parte da lingüística aplicada, uma vez que seu objeto de base é a linguagem em sua dimensão comunicativa. O que evidencia o aspecto comunicativo da terminologia é o fato do vocabulário temático encontrar-se em todas as áreas de domínio especializado (KRIEGER, 2001).

A prática terminológica, a terminografia, consiste em coletar e organizar os termos e as noções de uma área de conhecimento, sob a forma de repertórios: glossários, dicionários, etc., de acordo com os objetivos específicos determinados pelas necessidades dos usuários.

Com base nos estudos realizados até o momento, observa-se que existe a necessidade de identificar a terminologia utilizada em inteligência competitiva organizacional, com o fim de estabelecer a representação e divulgação do conhecimento, seja com a finalidade puramente científica da base conceitual, seja com vistas à fixação e uso dos termos, por meio do estabelecimento de um registro padrão bem fundamentado.

Conforme Valentim et al. (2003, p.1), a inteligência competitiva organizacional, é o

Processo que investiga o ambiente onde a empresa está inserida, com o propósito de descobrir oportunidades e reduzir os riscos, bem como diagnostica o ambiente interno organizacional, visando o estabelecimento de estratégias de ação a curto, médio e longo prazo.

Para a constituição do corpus, isto é, "o conjunto dos documentos para serem submetidos aos procedimentos analíticos" (BARDIN, 
1997, p.96), visando à identificação das terminologias pertinentes à IC em organizações, foi utilizado o conjunto de textos relacionados para estudos no Grupo de Pesquisa, o qual contempla as diversas vertentes em estudo, a saber: Cultura e Clima Organizacional; Comunicação Informacional; Prospecção e Monitoramento Informacional; Gestão da Informação; Gestão do Conhecimento; Inovação e Redes; Tecnologias de Informação; e Atores do Processo de Inteligência Competitiva Organizacional.

Desse modo, foram consideradas como 'categorias' as oito vertentes acima citadas, e como subcategorias, os elementos identificados nos estudos realizados em cada categoria, tendo como propósito o agrupamento dos termos em ordem alfabética nas respectivas categorias (Anexo).

O estabelecimento da estrutura conceitual, ou categorização, tem a função de orientar e auxiliar o pesquisador na delimitação do domínio em estudo e na definição das categorias com as quais se pretende trabalhar. Para organização do conhecimento de um domínio, desde a sua representação até à recuperação, estudam-se os conceitos que compõem esse campo do conhecimento e as relações que se estabelecem entre eles.

As categorias designam aspectos particulares de uma determinada área, denominando os agrupamentos de termos. Podem ser utilizadas na análise das mais diversas áreas do conhecimento, tanto como nas relações a serem estabelecidas entre os elementos que compõem essas áreas. Portanto, as categorias não constituem dados universais, mas nomeiam agrupamentos feitos de acordo com propósitos institucionais, atendendo às necessidades de um público específico. A seguir, tendo como ponto de partida a sugestão de uma categorização, inclui-se a representação gráfica, visando ilustrar esse contexto (Figura 1).

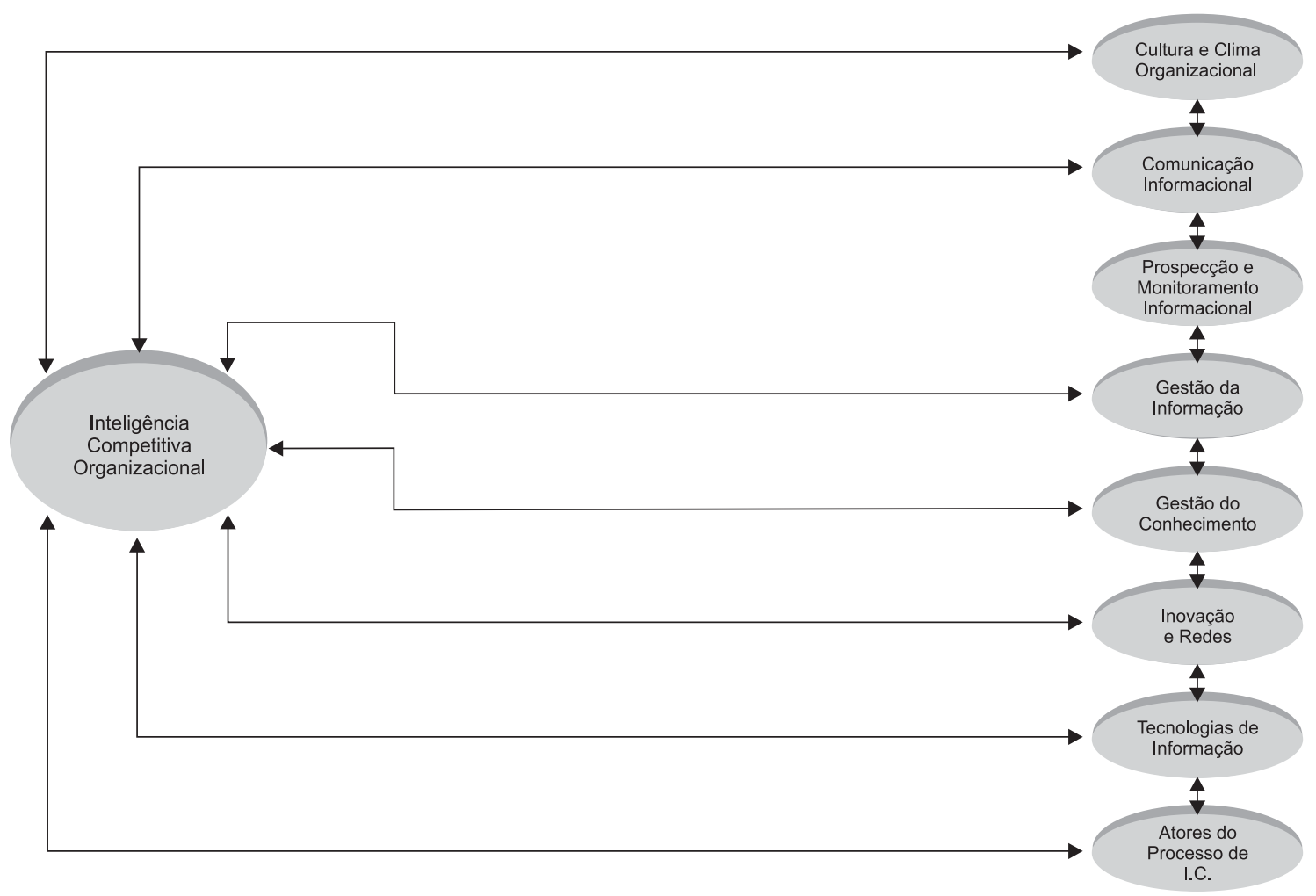

Figura 1. Categorias que compõe o Processo de Inteligência Competitiva Organizacional.

Fonte Adaptada: CERVANTES (2004). 
Cabe destacar que essas categorias constituintes interagem entre si e com o próprio processo de inteligência competitiva organizacional. Esta interação poderia resultar num modelo de relacionamento entre as categorias que se encontram representadas, conforme demonstra o diagrama acima.

O processo de coleta e confirmação dos termos foi realizado em duas fases. Convém esclarecer que na primeira fase optou-se por fazer um recorte do corpus representativo, acima referido, selecionando-se os artigos de periódicos publicados em língua portuguesa entre os anos de 1999 e 2002. A composição do corpus contou com um total de 79 artigos.

Para o processo de escolha dos artigos de periódicos, estabeleceu-se como critério, que fossem artigos identificados nos veículos de divulgação citados pelos Programas de PósGraduação na área de Ciência da Informação, e enquadrados no processo de classificação Qualis - concebido pela Capes, em categorias indicativas de qualidade - com pontuação $\mathrm{A}$ (alta) no ano de 2002, com âmbito de circulação em nível nacional.

Dentre as publicações periódicas da área de Ciência da Informação que obtiveram pontuação A, em nível nacional, no ano de 2002, no processo de classificação Qualis/Capes, elegeu-se para o trabalho os seguintes títulos: Ciência da Informação; DataGramaZero; Perspectivas em Ciência da Informação e Transinformação.

Cabe ressaltar que a vantagem do levantamento de termos por meio dos periódicos especializados, consiste na obtenção de termos atualizados com o grau de desenvolvimento da área e identificados pelos pares. Conforme os estudos de King e Tenopir (1998, p.176), os artigos de periódicos são lidos com maior freqüência do que os de qualquer outro tipo de publicação, seja esta uma revista comercial, um livro, ou relatório técnico, etc.; ademais, os leitores pesquisadores buscam nessas leituras atualização e informação para seus estudos e para o ensino/aprendizagem.
1) Primeira fase da coleta e confirmação de termos:

- análise do corpus, buscando a identificação dos termos em seus contextos de ocorrência. Explica Krieger (2004, p.119): "a investigação sobre os termos não pode desconsiderar seus contextos de ocorrência". No momento da identificação, os candidatos a termos foram registrados em fichas terminológicas;

- entrevista com especialistas da área para a confirmação ou não dos candidatos a termos, conforme os paradigmas: preferido, não-preferido, desconhecido, recusado.

2) Segunda fase da coleta e confirmação de termos:

- análise dos questionários respondidos pelos sujeitos da pesquisa visando obter terminologia sobre IC. No instante da identificação, os candidatos a termo em seus contextos de ocorrência foram registrados em fichas terminológicas;

- entrevista com os especialistas da área para a confirmação dos candidatos a termos, conforme os paradigmas: preferido, não-preferido, desconhecido, recusado.

Após o término destes procedimentos, reuniram-se os termos identificados e confirmados, na primeira e segunda fases, para verificação de inconsistências, adequações necessárias e estabelecimento das relações entre os mesmos. Em seguida, foi elaborado um repertório contendo os termos acompanhados de seus contextos de ocorrência.

\section{CONSIDERAÇÕ ES PARCIAIS}

A análise de conteúdo, neste caso, utilizando-se de duas técnicas, quais sejam, a análise léxica e a análise categorial, é muito complexa, exigindo do pesquisador um olhar crítico sobre os dados analisados. 
Os procedimentos metodológicos, descritos detalhadamente neste artigo, são resultado do estudo sobre a análise de conteúdo, bem como do estudo comparativo entre diferentes propostas metodológicas de coleta e análise de dados.

Nesta pesquisa, a análise categorial (temas) propicia desenvolver-se a análise qualitativa, tendo em vista, primeiramente, compreender o fenômeno, conhecer o objeto pesquisando-o mais profundamente e, portanto, construir novos conhecimentos.

Sua aplicação qualitativa permite ao pesquisador realizar inferências, por meio da observação do estado de espírito e contexto dos sujeitos ou grupos pesquisados. Para Freitas e Janissek (2000, p.37), a análise categorial (temas), aplicada à análise de conteúdo,

[...] pode ser usada para analisar em profundidade cada expressão específica de uma pessoa ou grupo envolvido num debate [...] Permite também observar motivos de satisfação, insatisfação ou opiniões subentendidas, natureza de problemas, etc., estudando as várias formas de comunicação.

Ao contrário, a análise léxica essencialmente quantitativa, exige do pesquisador uma organicidade em relação aos temas, categorias, subcategorias e vocabulário pesquisados. Ela permite ao pesquisador obter indicadores importantes para a realização da análise de conteúdo. Além disso, a análise léxica possibilita reconhecer a terminologia mais usada pelos indivíduos ou grupos pesquisados.

Em conclusão, esta pesquisa em inteligência competitiva organizacional, utilizando-se da análise de conteúdo para a coleta e análise de dados, propiciará a construção de conhecimento para a área de IC, identificando, inclusive, a terminologia de IC usada na região geopolítica do Norte do Estado do Paraná, e compartilhando os resultados com a comunidade científica da área.

\section{REFER Ê N CIAS}

ADAMS, G.L.; LAMONT, B.T. Knowledge management systems and developing sustainable competitive advantage. Journal of Knowledge Management, v.7, n.2, p.142-154, 2003.

ALBERTIN, A.L. Valor estratégico de projetos de tecnologia de informação. Revista de Administração de Empresas, São Paulo, v.41, n.3, p.42-50, 2001.

BARDIN, L. Análise de conteúdo. Lisboa: Edições 70, 1977. 226p.

BERNARDES, R.; ALMEIDA, E.S. Nova função empresarial na coordenação de redes de inovação. Revista da Sociedade Brasileira de Economia Política, Rio de Janeiro, n.5, p.86-120, 1999.

BURK JR., C.F.; HORTON, F.W. Infomap: a complete guide to discovering corporate information resources. Englewood Cliffs: Prentice Hall, 1988. 233p.

CARVALHO, E.L. Informação orgânica: recurso estratégico para tomada de decisão pelos membros do Conselho de Administração da Univer- sidade Estadual de Londrina. Campinas, 2001. $93 f$. Dissertação (Mestrado em Biblioteconomia) - Faculdade de Biblioteconomia, Pontifícia Universidade Católica de Campinas, Campinas, 2001.

CERVANTES, Brígida Maria Nogueira. Contribuição para a terminologia do processo de inteligência competitiva: estudo teórico e metodológico. Marília, 2004. 183f. Dissertação (Mestrado em Ciência da Informação) - Faculdade de Filosofia e Ciências, Universidade Estadual Paulista, Marília, 2004.

CHIAVEGATTO, M.V. As práticas do gerenciamento da informação: estudo exploratório na Prefeitura de Belo Horizonte. Belo Horizonte, 1999. $112 f$. Dissertação (Mestrado em Administração Pública) - Escola do Governo, Fundação João Pinheiro, Belo Horizonte, 1999.

CHOO, C. W. A organização do conhecimento: como as organizações usam a informação para criar significado, construir conhecimento e tomar decisões. São Paulo: Senac, 2003. 425p. 
CIANCONI, R. Gestão da informação na sociedade do conhecimento. Brasília: SENAI/DN, 1999.

CORREIA, A.M.R.; SARMENTO, A. Gestão do conhecimento: competências para inovação e competitividade. In: ENCONTRO NACIONAL DE SOCIOLOGIA INDUSTRIAL DAS ORGANIZAÇÕES E DO TRABALHO (APSIOT). Lisboa: Fundação Calouste Gulbenkian, 27-28 mar. 2003. Disponível em: <http://www.isegi.unl.pt/ensino/docentes/ acorreia/preprint/APSIOT_Correia_Sarmento.pdf>. Acesso em: 23 nov. 2003.

DAVENPORT, T.H. Ecologia da informação: por que só a tecnologia não basta para o sucesso na era da informação. São Paulo: Futura, 1998. 316p.

DEMANTOVA NETO, C.; LONGO, R.M. A gestão do conhecimento e a inovação tecnológica. Transinformação, Campinas, v.13, n.2, p.93-110, 2001.

DOSI, G. et al. Technical change and economic theory. London: Printer Publishers, 1988.

DREBRESSON, C.; AMESE, F. Networks of innovators: a review and introduction to the issue. Research Policy, Orlando, v.20, n.5, p.363-379, 1991.

FREITAS, H.M.R.; LESCA, H. Competitividade empresarial na era da informação. Revista de Administração, São Paulo, v.27, n.3, p.92-102, 1992.

FREITAS, H.; JANISSEK, R. Análise léxica e análise de conteúdo: técnicas complementares, seqüenciais e recorrentes para análise de dados qualitativos. Porto Alegre: Sphinx, 2000. 176p.

GARTON, L.; HAYTHORNTHWAITE, C.; WELLMAN, B. Studying online social networks. JMC - Journal of Computer-Mediated Communication, v.3, n.1, Jun. 1997. Available from: <http://www.ascusc.org/jcmc/ vol3/issue1/garton.html>. Acess: 21 Jun. 2003.

GOMES, E.; BRAGA, F. Inteligência competitiva: como transformar informação em um negócio lucrativo. Rio de Janeiro: Campus, 2001. 128p.

HAVEHGA, J.; BOTHA, D. Developing competitive intelligence in the knowledge-based organization. In: SOUTHERN AFRICAN ONLINE INFORMATION MEETING, 7., Jun. 2003. Available from: <http:// www.saoug.org.za/archive/2003/0312a.pdf>. Acess: 20 Jan. 2004.

JOHNSON, B.; LUNDVALL, B.A. Promoting innovation systems as a response to the globalizing learning economy. In: CASSIOLATO, J.E.; LASTRES,
H.M.M. Arranjos e sistemas produtivos locais e as novas políticas de desenvolvimento industrial e tecnológico. Rio de Janeiro: IE/UFRJ, 2000. Disponível em: <http://www.druid.dk/summer2000/ Gallery/nyjohnson \&lundvall.pdf>. Acesso em: 13 out. 2003.

KIELGAST, S., HUBBARD, B.A. Valor agregado à informação: da teoria à prática. Ciência da Informação, Brasília, v.26, n.3, p.271-276, 1997.

KING, D.W.; TENOPIR, C. A publicação de revistas eletrônicas: economia da produção, distribuição e uso. Ciência da Informação, Brasília, v.27, n.2, p.176-182, 1998.

KRIEGER, M.G. A face lingüística da terminologia. In: TEMAS de terminologia. São Paulo: Humanitas/ FFLSH-USP, 2001. p.22-33.

KRIEGER, M.G.; FINATTO, M.J.B. Introdução à terminologia: teoria e prática. São Paulo: Contexto, 2004.

KROG, G.V.; ICHIJO, K.; NONAKA, I. Facilitando a criação de conhecimento: reinventando a empresa com o poder da inovação contínua. Rio de Janeiro: Campus, 2001. 350p.

KRÜCKEN-PEREIRA, L.; DEBIASI, F.; ABREU, A.F. Inovação tecnológica e inteligência competitiva: um processo interativo. Revista Eletrônica de Administração, v.7, n.3, jul. 2001. Disponível em: <http://read.adm.ufrgs.br/read21/artigo/artigo5. pdf>. Acesso em: 28 nov. 2002.

MAÇADA, A.C.G.; BECKER, J.L. O impacto da TI na estratégia dos bancos. Revista de Administração de Empresas, São Paulo, v.41, n.4, p.87-97, 2001. MINISTERIO DA CIÊNCIA E TECNOLOGIA. Programa Prospectar. Disponível em: <http:// www.mct.gov.br/cct/prospectar/Programa/ apresenta\%C3\%A7\%C3\%A30.htm>. Acesso em: 28 mar. 2003.

MOLINA, J.L. La ciencia de las redes. Apuntes de Ciencia y Tecnología, n.11, p.36-42, jun. 2004. Disponible en: <http://seneca.uab.es/antropologia/ jlm/public_archivos/ciencia.pdf>. Acceso en: 12 set. 2004.

NONAKA, I.; TAKEUCHI, H. Criação de conhecimento na empresa: como as empresas japonesas geram a dinâmica da inovação. 9.ed. Rio de Janeiro: Campus, 1997. 358p.

PALOP, F.; VICENTE, J.M. Vigilancia tecnológica e inteligencia competitiva: su potencial para la empresa española. Madrid: COTEC, 1999. 107p. 
Disponible en: <www.innovarium.com/Innovacion/ innovacion\%20tecnologia.htm>. Acceso en: $7 \mathrm{fev}$. 2002.

PONJUÁN DANTE, G. Gestión de información en las organizaciones: principios, conceptos y aplicaciones. Santiago: CECAPI, 1998. 222p.

REZENDE, D.A.; PEREIRA, R. Sistemas de conhecimentos gerados pelos recursos da Tecnologia da Informação. In: SIMPÓSIO INTERNACIONAL SOBRE GESTÃO DO CONHECIMENTO, 5., 2002, Curitiba. Anais... Curitiba: ISKM2002, 2002.

SANTOS, R.N.M. Métodos e ferramentas para gestão de inteligência e do conhecimento. Disponível em: <http://www.mdic.gov.br/tecnologia/ revistas/artigos/200104mg/art05raimundo.pdf>. Acesso em: 10 abr. 2001.

SCHUMPETER, J.A. Teoria do desenvolvimento econômico: uma investigação sobre lucros, capital, crédito, juro e o ciclo econômico. [S.I.]: Victor Civita, 1982.

TEIXEIRA FILHO, J. Gerenciando conhecimento: como a empresa pode usar a memória organizacional e a inteligência competitiva no desenvolvimento de negócios. Rio de janeiro: SENAC, 2000. 191p.

TEIXEIRA FILHO, J. Planejamento tecnológico para vantagem competitiva. Disponível em: <http:// www.informal.com.br/artigos/art020.htm,2001>. Acesso em: 10 abr. 2001.

TERRA, J.C.C. Gestão do conhecimento: o grande desafio empresarial. São Paulo: Negócio Editora, 2000. 283p.

VALENTIM, M.L.P. Comunicação organizacional no processo de inteligência competitiva. Infohome, Londrina, 2003a. Disponível em: <http://www.ofaj. com.br/colunaicgc_mv_1203.html>. Acesso em: 18 dez. 2003.

VALENTIM, M.L.P. et al. O processo de inteligência competitiva em organizações. DataGramaZero, Rio de Janeiro, v.4, n.3, p.1-23, jun. 2003. Disponível em: <http://www.dgz.org.br/jun03/Art_03.htm>. Acesso em: 3 jul. 2003.

VALENTIM, M. L. P. Cultura organizacional e gestão do conhecimento. InfoHome, Londrina, 2003b. Disponível em: <http://www.ofaj.com.br/ colunaicgc_mv_0303.html>. Acesso em: 29 set. 2004.

VALENTIM, M.L.P. Comunicação organizacional no processo de inteligência competitiva (2). Infohome, Londrina, 2004a. Disponível em: <http:// www.ofaj.com.br/colunaicgc_mv_0104.html>. Acesso em: 18 jan. 2004.

VALENTIM, M. L. P. Equipes multidisciplinares na gestão da informação e do conhecimento. In: BAPTISTA, S.G.; MUELLER, S.P.M. (Org.). Profissional da informação: o espaço de trabalho. Brasília: Thesaurus, 2004b. p.154-176 (Estudos Avançados em Ciência da Informação, 3).

VALENTIM, M.L.P.; MOLINA, L.G. Prospecção e monitoramento informacional no processo de inteligência competitiva. Encontros Bibli: Revista Eletrônica de Biblioteconomia e Ciência da Informação, Florianópolis, 2004. Edição especial. Disponível em: <http://www.encontros-bibli.ufsc.br/ bibesp/sumario.htm>. Acesso em: 14 set. 2004.

VARGAS, L.M.; SOUZA, R.F. O ator de inteligência competitiva (IC) nas empresas: habilidades profissionais e exigências do mercado. Read - Revista Eletrônica de Administração, Porto Alegre, v.7, n.6, dez. 2001. Disponível em: <http://read. adm.ufrgs.br/read24/artigos/artigo5.pdf>. Acesso em: 28 nov. 2002 


\section{ANEXO}

\begin{tabular}{|c|c|}
\hline Categorias & Contexto de Ocorrência - conceitos/definições \\
\hline $\begin{array}{l}\text { Cultura e } \\
\text { Clima }\end{array}$ & $\begin{array}{l}\text { [...] A cultura organizacional voltada ao processo de IC é um } 1 \text { ) liderança; } \\
\text { processo de construcão da realidade coletiva, conduzido por um }\end{array}$ \\
\hline Organizacional & $\begin{array}{l}\text { líder, que define os melhores elementos e processos culturais, 3) valores da organização; } \\
\text { assim comooscomportamentos inerentes ao clima organizacional, 4) valores comportamentais } \\
\text { visando motivar os indivíduos por meio de realizações de dos indivíduos. }\end{array}$ \\
\hline
\end{tabular}
comportamento de informações, conhecimento, experiência e condutas que visam atingir o objetivo organizacional.

Comunicação Informacional

Prospecção e Monitoramento Informacional

Gestão da Informação

Gestão do Conhecimento
[...] processo contínuo que alimenta, reconhece, gera, usa e compartilha dados, informações e conhecimento existente no ambiente corporativo (VALENTIM, 2004a).

Propescção:

[...] método ou técnica que visa à identificação inicial de dados, informação e conhecimento relevantes para a organização (VALENTIM; MOLINA 2004). Monitoramento:

[...] método ou técnica de observação e acompanhamento constante de dados, informação e conhecimento relevantes ao negócio da organização (VALENTIM; MOLINA 2004).

[...] implica primeiramente, na identificação das necessidades informacionais das pessoas da organização, tendo como foco as metas e diretrizes organizacionais. O segundo passo visa, criar metodologias para mapear e reconhecer os fluxos formais de informação nos diferentes níveis hierárquicos, para finalmente buscar ferramentas (tecnologias de informação), objetivando coletar, tratar, analisar, armazenar, disseminar e medir as informações, subsidiando assim o processo decisório e as atividades cotidianas desenvolvidas voltadas aos produtos e serviços da corporação (CARVALHO, 2001).

[...] conjunto de estratégias para criar, adquirir, compartilhar e 1) motivação;

utilizar ativos de conhecimento, bem como estabelecer fluxos que garantam a informação necessária no tempo e formato adequados, a fim de auxiliar na geração de idéias, solução de problemas e tomada de decisão (VALENTIM, 2003b).
1) modelos comunicacionais;

2) uso da comunicação como instrumento de divulgação das normas da organização;

3) cultura em relação à comunicação;

4) redes de pessoas em relação à comunicação;

5) tipologias comunicacionais.

1) mapeamento das necessidades informacionais;

2) filtragem da informação;

3) agregação de valor;

4) disseminação da informação.

1) diretrizes para administrar a informação interna;

2) coleta de informações (fluxos formais);

3) organização da informação (tecnologia);

4) disseminação e mediação da informação.

2) comprometimento;

3) satisfação;

4) aprendizado;

5) compartilhamento de conhecimento 
continuação

\begin{tabular}{|c|c|c|}
\hline \multicolumn{3}{|c|}{ ANEXO } \\
\hline Categorias & Contexto de Ocorrência - conceitos/de & finições \\
\hline $\begin{array}{l}\text { Inovação de } \\
\text { Redes }\end{array}$ & $\begin{array}{l}\text { Inovação: } \\
\text { [...] novo produto, processo ou sistema que tem potencial para } \\
\text { criar um mercado inteiramente novo, ou mudar um mercado } \\
\text { existente, de tal maneira a criar padrões de competitividade ou } \\
\text { de comportamento do consumidor (BROWN apud DEMANTOVA } \\
\text { NETO; LONGO, 2001). } \\
\text { Constitui-se pela pesquisa, descoberta, verificação, desenvolvi- } \\
\text { mento, imitação e aceitação de novos produtos, novos processos } \\
\text { e novas técnicas organizacionais (DOSI, 1998). } \\
\text { Redes: } \\
\text { [...] conjunto de relações (elos ou vínculos) entre uma série } \\
\text { definida de elementos (nós - indivíduos, organizações, etc.), } \\
\text { com interesses e/ou objetivos comuns (MOLINA, 2004). }\end{array}$ & $\begin{array}{l}\text { 1) inovação e o processo } \\
\text { de inteligência competitiva } \\
\text { 2) relações entre gestão } \\
\text { do conhecimento e inova- } \\
\text { ção; } \\
\text { 3) sistema local de inova- } \\
\text { ção; } \\
\text { 4) redes de relaciona- } \\
\text { mento. }\end{array}$ \\
\hline $\begin{array}{l}\text { Tecnologias de } \\
\text { Informação }\end{array}$ & $\begin{array}{l}\text { [...] recursos tecnológicos e computacionais para guarda, geração } \\
\text { e uso da informação, e estão fundamentadas nos seguintes } \\
\text { componentes: hardware e seus dispositivos e periféricos; software } \\
\text { e seus recursos; sistemas de telecomunicações; gestão de } \\
\text { dados e informações (REZENDE E PEREIRA 2002). }\end{array}$ & $\begin{array}{l}\text { 1) gestão/investimento em } \\
\text { TI's; } \\
\text { 2) ferramentas utilizadas } \\
\text { no processo; } \\
\text { 3) atores/setores da orga- } \\
\text { nização que utilizam a TI's. }\end{array}$ \\
\hline $\begin{array}{l}\text { Atores do } \\
\text { Processo de } \\
\text { Inteligência } \\
\text { Competitiva } \\
\text { Organizacional }\end{array}$ & $\begin{array}{l}{[. . .] \text { todas as pessoas atuantes na organização, com formação }} \\
\text { e competências específicas, visando o desenvolvimento de } \\
\text { atividades informacionais relacionadas ao negócio corporativo } \\
\text { (VALENTIM, 2004b). }\end{array}$ & $\begin{array}{l}\text { 1) competências e habili- } \\
\text { dades; } \\
\text { 2) formação profissional; } \\
\text { 3) função/responsabilida- } \\
\text { des; } \\
\text { 4) setores específicos/ } \\
\text { equipes multidisciplinares. }\end{array}$ \\
\hline
\end{tabular}

